\title{
IMPLICATIONS OF SYMPATHY, EMPATHY AND APATHY IN MEDICO-LEGAL PRACTICE
}

\author{
Ariyarathne $D^{1}$ Hulathduwa $S \mathbf{R}^{2}$ \\ 1,2 Dept. of Forensic Medicine, Faculty of Medical Sciences, \\ University of Sri Jayawardenepure, Nugegoda, Sri Lanka
}

\begin{abstract}
The terms sympathy and empathy have subtly different meanings. Sympathy is the caring, concern and understanding for the suffering of others while empathy refers to being-putting oneself in the place of an aggrieved party. Apathy means lack of feeling, emotion, interest or concern which leads the individual to a state of indifference. This article is aimed at creating a dialogue among medico-legal practitioners as to what extent should empathy or sympathy be shown to their clients.
\end{abstract}

Expression of sympathy or empathy by medico-legal professionals in Sri Lanka may be limited because of several reasons. As the prime concern of a medico-legal professional is to gather information for a court of law, this may require him to be more factually oriented without taking emotions into account. Emotional involvement in a case may cloud the professional's judgement. Furthermore, as medico-legal professionals see many emotionally agonising cases on a daily basis, one might find it traumatising to become emotionally involved in each case. Unless the practicing doctors are appropriately trained in life skills such as the desired method of reacting in front of the patients, bereaved relatives and other concerned parties, the overwhelming reactions to emotions would make the practitioner trespass the professional boundaries. However if one reacts with apathy and indifference, the investigation process may be deficient and incomplete. It is important to strike a balance between 'caring too much' and 'caring too little'. However it is not easy to lay guidelines as to how much to react in a given setting. It should be judged by the practicing doctor using common wisdom and past experience. Therefore it is important to address the matter from the very first stages of postgraduate training in Forensic Medicine.

Key Words: sympathy, empathy, medicolegal practice, emotional labiality

\section{INTRODUCTION}

The terms sympathy and empathy are often used similarly and interchangeably though their emotional meaning is subtly different. In simple terms, sympathy is the caring, concern and understanding for the suffering of others-the concern for the well-being of another. Empathy refers to the understanding and sharing of a specific emotional state with a fellow human being-putting oneself in the place of the aggrieved party. A person expresses sympathy while he shares empathy. When sympathising, one recognizes that another person is suffering while when empathising, the person's pain or suffering is felt. As such, empathy is a deeper feeling compared to sympathy ${ }^{1,2}$. The origin of the word sympathy comes from the old Greek terms syn (meaning together) and pathos (meaning to feel). The term empathy was coined by the British psychologist Edward Titchener in 1909 to translate the meaning of a German word which meant "shared feeling".

Sympathy and empathy are both complex feelings, which, though, are neither the same 
nor are mutually exclusive. One may feel both together as the bases for both are the compassion blended with understanding and acceptance of others enhanced by knowledge and wisdom. Thus, the capacity to sympathize and empathize is considered as features of humanity.

On the other hand apathy means lack of feeling, emotion, interest or concern which leads the individual to a state of indifference. Such an individual may show lack of interest in emotional, social, cultural, spiritual and philosophical aspects of life as well as physical life and worldly events. Apathy may arise when the individual feels that he does not possess the level of skill required to confront and overcome a challenge. This type of transient feelings will be experienced by almost all individuals at some point in life and as such it is considered a natural response to disappointment, stress and dejection as it helps to forget these negative feelings. Long standing apathy may be a sign of more specific mental disorders such as schizophrenia or dementia. Extremely apathetic individuals (together with other behavioural abnormalities) will be classified as narcissistic, sociopathic or psychopathic ${ }^{3}$.

This article is aimed at creating a dialogue among medico-legal practitioners as to what extent should empathy or sympathy be shown to their clients.

\section{DISCUSSION}

\section{Sri Lankan practice}

The existent practice in the country is that the same medico-legal specialist deals with both autopsies and clinical cases. The prime concern of the medico-legal specialist is gathering information so as to provide evidence to courts of law in the form of documents and verbal evidence. There are legal as well as customary restrictions towards a wide array of other forms of communication and contacts with the interested parties who may be the representatives of the clinical client (examinee), the senior next of kin of the deceased or certain other parties legally, socially and culturally interested about the case or the situation. Trends are positively changing. Yet, the "holistic" and "therapeutic" nature of the approach which is currently available in the developed countries is not yet fully established in Sri Lanka. Thus the medico-legal specialist may lack an opportunity to express sympathy or empathy and take further steps based on these emotions for the good will of his client (or other interested parties). Forensic Medical Specialists are in a way "forced" to be apathetic and show indifference in certain situations.

On the other hand the prime expectation from the medico-legal specialist is that he gives scientifically solid, unbiased, impartial, accurate and truthful evidence and opinion within his capacity. Certain emotions that they invariably encounter during clinical medico-legal work as well as death investigations might adversely affect this ideal expectation. In other words, the medico-legal specialist should not be emotionally biased.

\section{Impact on personal and professional life}

Clinical Forensic Medicine and Forensic Pathology are the two topmost medical disciplines where the practitioners very commonly and frequently receive extremely emotionally agonizing and psychologically traumatizing first-hand information in the form of history, examination and investigative results. This, they receive not in an ad-hoc manner (like emergency department surgeons) but in a continuous daily basis as long as they are involved in active practice. The short-term and long-term impacts of this on the doctor's psychological well-being as well as the defence mechanisms in operation in the mind-set of the doctor (such as dissociation) and the long-term personality and behavioural 
implications upon the doctor are much underresearched.

Unless the practitioner employs his common human wisdom as well as the experience he has gained over the years to measure the right amount of human response that should be ideal for the occupational demands in relation to the challenging situation before him, he may be emotionally overwhelmed by sympathy and over react to the situation to the extent that his evidence and opinion will be biased and un impartial ${ }^{1,4}$. On the other hand, if he under-reacts in apathy and indifference, not only that his client -dead or alive- will not receive the bare minimum of his due but also the investigative process may become deficient and incomplete.

Being less sensitive to an incident may be due to varied reasons. Lacking in awareness, knowledge, experience or skills to overcome the situation would make one lethargic towards an incident. This does not imply an abnormal behaviour. However it is important to care for the people in front of you and do the needful without getting personally and emotionally attached or detached.

Boundaries in between empathy and sympathy at times may be blurred. Yet, the doctor must maintain the objectives of his professional duty consciously, rather than merging with the emotions under the "wrong impression" that he perceives the situation accurately. This emotional labiality may drive a doctor into troublesome and unprofessional pathways. In extreme cases it might lead to personal sympathetic relationships with the patients or relatives, which is considered highly unethical. Codependency and professional burn-outs are other undesired consequences of being emotionally labile ${ }^{5,6}$.

\section{Moulding of characters and developing life-skills}

All doctors deal with human life in different aspects, stages and forms. Forensic practitioners deal with legal aspects of human life mostly merged with the quality, freedom and dignity of life. Unless the practicing doctors are appropriately trained in life skills such as the desired method of reacting in front of the patients, bereaved relatives and other concerned parties, the overwhelming reactions to emotions (not only sympathy and empathy but also anger, disgust, passion and repulsion at times) would make the practitioner trespass the professional boundaries ${ }^{7}$. This experience should be gained during formal postgraduate training and it is the responsibility of the supervisors to assess the degree of acquisition of skills in this aspect.

\section{CONCLUSION AND RECOMMENDATIONS}

Novice practitioners in the field of forensic medicine may encounter many cases where they are psychologically entangled with the emotions of the examinees and the kiths and kins of the deceased. Such encounters may tarnish professional image as well as lead to complexities in personal life. In the long run, over-reacting as well as under-reacting to patient's emotions will have a negative impact upon the field. It is not easy to lay guidelines as to how much to react in a given setting. How much is too much and how much is too little has to be clearly judged by the practicing doctor using common wisdom and past experience. Only then will the client either alive or dead will be able to experience the broadest sense of real natural justice. 


\section{REFERENCES}

1. Elliot M. Hirsch MD, Illuminating the art of medicine, Virtual Mentor. June 2007, Volume 9, Number 6: 423-427

2. Lishner D A. Baston C D. Huss E. Tenderness and Sympathy-Personality and Social Psychology Bulletin 2011, 37 (5),614625

3. Narcissistic personality disorder Diagnostic and Statistical Manual of Mental Disorders Fourth edition Text Revision (DSM-IV-TR) American Psychiatric Association (2000)

4. Bellet, Paul S., and Michael J. Maloney (1991). "The importance of empathy as an interviewing skill in medicine". JAMA 226 (13): 1831-1832.
5. Decety, J; Michalska, KJ (2010). "Neurodevelopment changes in the circuits underlying empathy and sympathy from childhood to adulthood". Developmental Science 13 (6): 886-899.

6. Melody Beattie, Beyond Co-dependency: And Getting Better All the Time., Hazelden, 2013

7. MaibomHL, Empathy: Philosophical and Psychological Perspectives, edited by Amy Coplan and Peter Goldie. Mind (2014) 123 (491) 